\title{
DEVELOPMENT OF A RISK SCREENING METHOD FOR CREDITED OPERATOR ACTIONS
}

James C. Higgins, John M. O'Hara, Paul M. Lewis, J. Persensky and J. Bongarra

May 15, 2002

\section{Energy Sciences \& Technology}

Brookhaven National Laboratory

Operated by

Brookhaven Science Associates

Upton, NY 11973 


\section{DISCLAIMER}

This report was prepared as an account of work sponsored by an agency of the United States Government. Neither the United States Government nor any agency thereof, nor any of their employees, nor any of their contractors, subcontractors or their employees, makes any warranty, express or implied, or assumes any legal liability or responsibility for the accuracy, completeness, or any third party's use or the results of such use of any information, apparatus, product, or process disclosed, or represents that its use would not infringe privately owned rights. Reference herein to any specific commercial product, process, or service by trade name, trademark, manufacturer, or otherwise, does not necessary constitute or imply its endorsement, recommendation, or favoring by the United States Government or any agency thereof or its contractors or subcontractors. The views and opinions of authors expresses herein do not necessarily state to reflect those of the United States Government or any agency thereof. 


\title{
Development of a Risk Screening Method for Credited Operator Actions
}

\author{
James C. Higgins, Senior Member, IEEE, John M. O’Hara, Paul M. Lewis, J. Persensky, and J. Bongarra
}

\begin{abstract}
The US Nuclear Regulatory Commission (NRC) reviews the human factors aspects of proposed license amendments that impact human actions that are credited in a plant's safety analysis. The staff is committed to a graded approach to these reviews that focus resources on the most riskimportant changes. Therefore, a risk-informed screening method was developed based on an adaptation of existing guidance for risk-informed regulation and human factors. The method uses both quantitative and qualitative information to divide the amendment requests into different levels of review. The method was evaluated using a variety of tests. This paper will summarize the development of the methodology and the evaluations that were performed to verify its usefulness.
\end{abstract}

Index Terms - human factors, nuclear power generation control, nuclear power generation safety, risk analysis, safety.

\section{NOMENCLATURE}

CDF core damage frequency

EOP emergency operating procedure

HA human action

HEP human error probability

HF human factors

HSI human system interface

ISI inservice inspection

LERF large early release frequency

mod modification

NRC Nuclear Regulatory Commission

PSA probabilistic safety assessment

QA quality assurance

RG regulatory guide

SDP significance determination process

\section{INTRODUCTION}

Phe he U. S. Nuclear Regulatory Commission (NRC) reviews changes in operator actions that are credited in plant safety analyses. Changes in credited action may result from a variety of plant activities such as: plant modifications, procedure changes, equipment failures, and identified discrepancies in equipment

This work was supported by the Nuclear Regulatory Commission.

J. C. Higgins is with Brookhaven National Laboratory, Upton, NY 11973 USA (e-mail: higgins@bnl.gov).

J. M. O'Hara is with Brookhaven National Laboratory, Upton, NY 11973 USA (e-mail: ohara@bnl.gov).

P. Lewis is with the U. S. Nuclear Regulatory Commission (e-mail: pml1@nrc.gov)

J. Persensky is with the U. S. Nuclear Regulatory Commission (e-mail: jjp@nrc.gov)

J. Bongarra is with the U. S. Nuclear Regulatory Commission (e-mail: jxb@nrc.gov) performance or safety analyses. Relevant review considerations have been described in NRC information notices and generic letters. Generic Letter 91-18 [1] discusses the conditions under which manual actions may be used in place of automatic actions for safety system operations. Information Notice 97-78 [2] alerts licensees to the importance of considering the effects on human performance of such changes made to plant safety systems. Over the years the NRC's review approach to such changes in operator actions has evolved, both in terms of what aspects of the change would be reviewed and specifically what the review criteria are. In keeping with the general trend toward risk-informed regulation, the staff undertook to establish a risk screening methodology with the assistance of Brookhaven National Laboratory (BNL).

\section{Desired Features of Methodology}

In developing the risk-informed methodology, BNL first sought to articulate the broad properties such a method should possess in order to guide its development. In general it was desired to screen the submitted human actions into three risk levels or Regions and then develop a graded human factors (HF) review approach such that the more risk-significant HAs would receive a more detailed review. The most risk-significant actions would be placed in what is called Region I, the moderately important actions into a Region II and the least important into Region III. We needed to develop a risk screening method with appropriate measures and acceptance criteria that would define the three different Regions. We also needed to develop a graded HF review approach that could be applied to the three types of HAs. This HF approach was developed from existing HF review methods described in NUREG-0711 [3] and NUREG0700 [4] and is not discussed in this paper.

The desired features proposed for the risk measures and acceptance criteria were:

1. Discriminates the HAs into three levels of importance.

2. Selects the most important HAs for the Region I review.

3. Does not select an excessive number of HAs for Region I.

4. Screens out all unimportant HAs.

5. Easy to calculate.

6. Relates to the Commission's [5] quantitative risk goals (i.e., goals related to CDF and LERF).

7. Utilizes existing risk methods as much as possible.

IV. Approaches Developed

\section{Early development}

The first step in developing a method was to review a reasonably large selection of HAs that had been submitted to NRC for approval of the changes. This would allow us to see the scope of the problem and how much review the various types of actions had received in the past. Twenty-one past cases were reviewed as a first task in the 
project. There was broad variation in the types of changes reviewed over the 21 past cases, many reasons for the plant modifications, many different safety functions impacted, and many types of human actions affected. We judged some of the actions as being risksignificant. However, the percentage of risk important actions was low. This variation in risk level indicates that the risk-graded guidance approach that was being considered was in fact needed and that it should be beneficial in reducing the NRC effort and licensee burden associated with these types of review activities.

Also, a variety of current, risk-informed, regulatory documents and methods were reviewed to obtain a sample of possible methods that could be either used directly or adapted for use in this new application (see reference list here and in [6]). The most useful were found to be the NRC Safety Goals [5], Regulatory Guide (RG) 1.174 [7], RG 1.177 [8], and Azarm, et al. [9].

\section{NUREG/CR-6689 Method}

Based upon this information the proposed approach presented in NUREG/CR-6689 [10] was developed. This approach was fairly comprehensive in that it:

- $\quad$ addressed licensee submittals, whether or not they contained risk information;

- $\quad$ addressed modifications in which only human actions (HAs) were changed and modifications that were broader and included equipment changes as well
- $\quad$ considered both level 1 risk $(\triangle \mathrm{CDF})$ and level 2 risk (LERF);

- $\quad$ had screening tools for both permanent and temporary changes to HAs;

- $\quad$ presented detailed HF review criteria for both Region I and Region II HAs.

Here we will discuss only a submittal with risk information, and will consider only the CDF aspects for a permanent change. The main approach in NUREG/CR-6689 was based on the Figures of RG 1.174 as follows. Since a modification (mod) in the plant may include both equipment and HAs, one first determines the risk importance of the entire modification, using the methods of RG 1.174. When using a plant-specific PSA, the licensee (or NRC) should calculate the change in risk due to the modification $\left(\triangle \mathrm{CDF}_{\text {mod }}\right)$ that includes the new human action, as follows:

$$
\Delta \mathrm{CDF}_{\mathrm{mod}}=[\text { new CDF (with modification in-place) - }
$$
current baseline $\mathrm{CDF}]$

where: $\triangle \mathrm{CDF}_{\text {mod }}$ is the change in Core Damage Frequency due to the modification.

The value $\Delta \mathrm{CDF}_{\text {mod }}$ is then placed to one of the three Regions of Figure 1, Acceptance Guidelines for Core Damage Frequency.

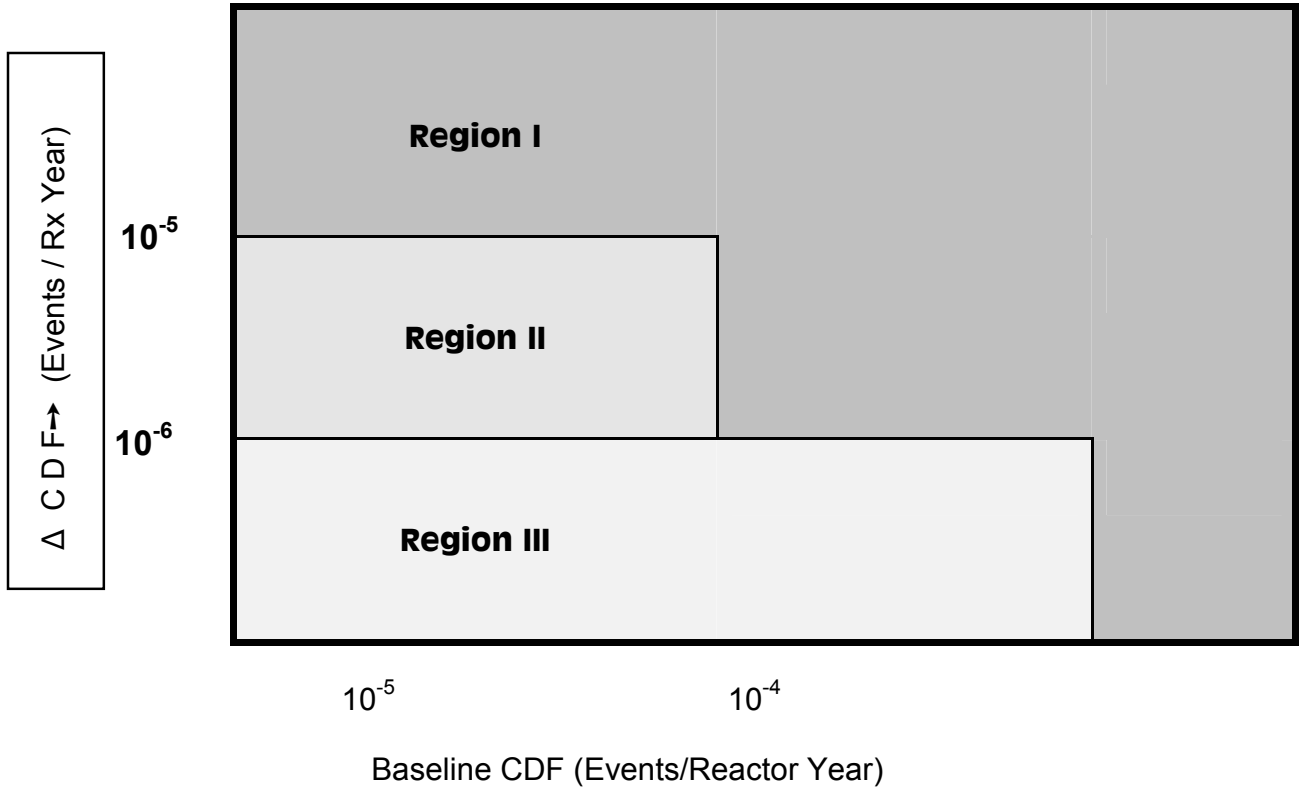

Figure 1 Acceptance Guidelines for Core Damage Frequency (CDF)

(Adapted from Figure 3 of RG 1.174) 
After determining the risk due to the entire modification, one next addresses the risk related to the HA. To do this we consider the risk significance of not performing the human action correctly. For this step, utilize the $\Delta \mathrm{CDF}_{\mathrm{HA}}$, which is the change in risk due to the failure of the new HA. It is defined as:

$\Delta \mathrm{CDF}_{\mathrm{HA}}=\mathrm{RAW}_{\text {Interval. }}$ (new HA) $=[\mathrm{CDF}$ with new HA failed - new CDF (with mod in-place)].

Use the value $\Delta \mathrm{CDF}_{\mathrm{HA}}$ to place the modification into one of the three Regions of Figure 1. The Risk Achievement Worth (RAW) importance measure is discussed in NUREG/CR-3385 [11]. For this application the interval method of calculating the RAW was selected. While the ratio method is more common now, the interval method gives equivalent results. Further, use of the interval method allows the use of the same Figure 1 and the same acceptance criteria that separate the three Regions of the figure for both Step 1 and Step 2 of this methodology. This is important since the figures and values dividing the Regions come from RG 1.174. This method gave reasonable results when tested as discussed in Section V. below.

\section{Modifications to Method}

The proposed method in NUREG/CR-6689 was published and made available as proposed method for consideration and comments were received from several sources. Some concerns were raised regarding a use of RG 1.174 figures that was not originally intended, namely entering with RAW values on the $y$-axis rather than $\triangle \mathrm{CDF}$. The concern here would be using the Figures for an extreme case of the HA being considered to fail rather than for a new base case HEP. Other comments were that use of RAW values for screening purposes is acceptable, but preferred to use the ratio method of presentation of RAW rather than the interval method as is done in the NUREG/CR. Even though the two methods of presenting RAW are mathematically equivalent and give the same screening results, it was noted that many applications currently use the ratio method, people are familiar with it, and PSAs typically already calculate RAW ratio values, so they are readily available. Requests were also made to add the use of the Fussell-Veseley (FV) importance measure to the screening. BNL was requested to consider using FV and RAW together and to consider the thresholds used in other risk-informed applications, such as graded QA [12] and risk-informed ISI [13]. Both the graded QA and risk-informed ISI approaches used the FV and the RAW ratio risk measures together in one plot.

As a result, BNL synthesized the past methods ([12] \& [13]) and produced another draft method (see Figure 2).

However, a difficulty with this second approach was that there is no consensus set of thresholds for RAW and FV that could readily be used for the splits between the risk Regions. The actual thresholds also differed among the various applications (e.g., QA, ISI, and maintenance rule) used to produce Figure 2. There was less agreement on thresholds for the FV measure than for the RAW measure. This is because the RAW can be easily related to $\triangle \mathrm{CDF}$, for which there are some agreed upon thresholds in various documents.

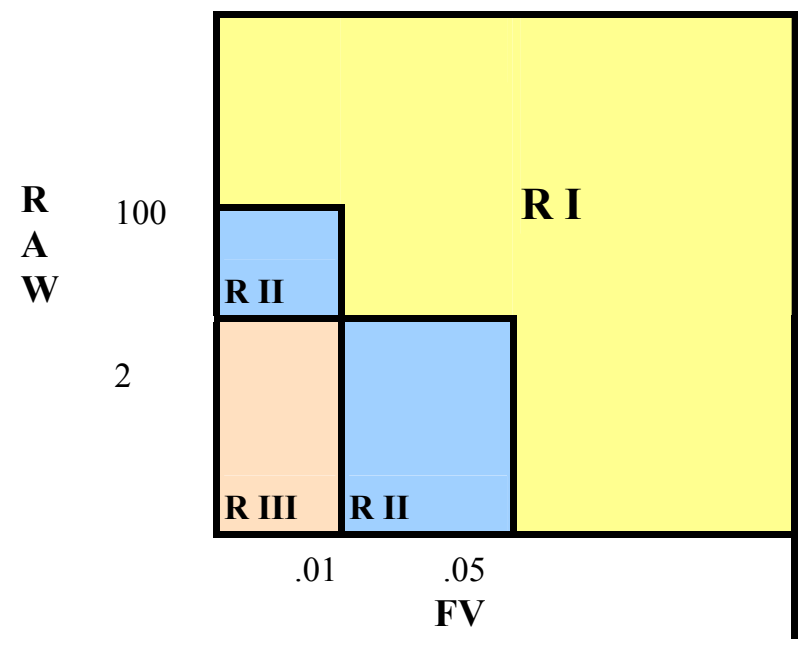

Figure 2 Synthesized Method for HA Screening

\section{Issue of Thresholds}

NRC and BNL then embarked on a two-pronged approach to address the question of the appropriate thresholds between the risk Regions that would be used for the graded HF review approach. First, BNL collected a relatively large amount of human action data from recent plant PSAs. This consisted of all HAs modeled in the PSA together with their RAW and FV values. We collected 127 HAs with RAW values greater than 1.0 from five different PSAs. These were plotted on a FV versus RAW chart to see if there were any natural clusters of the data (Figure 3). The thought was that perhaps with clustering and some expert judgement we could derive thresholds for the risk regions. However, we found no correlation between RAW and FV so that such an approach appeared not possible. This should not be surprising because the two risk measures define two different aspects of risk. RAW is a measure of the increase in CDF relative to the baseline CDF when the HA is assumed to fail (HEP set $=1.0$ ). Whereas, $\mathrm{FV}$ is a measure of the relative contribution of sequences containing the HA to the baseline CDF (with the HEP for the HA left at its base case value). Definitions are given below for the RAW ratio and the FV importance measures for a human action ' $\mathrm{x}$ ' in $\mathrm{a}$ plant PSA.

$\mathrm{RAW}_{\text {ratio }}(\mathrm{x})=\left(\mathrm{CDF}_{\mathrm{BL}}+\Delta \mathrm{CDF}_{\mathrm{x}}\right) / \mathrm{CDF}_{\mathrm{BL}}$

$\mathrm{FV}(\mathrm{x})=\sum$ all sequences containing $\mathrm{x} / \mathrm{CDF}_{\mathrm{BL}}$

Thus, while one would expect the two measures to give different results, the scatter of the plots was striking and lacked any discernable pattern (See Figure 3 below). 


\section{RAW vs FV}

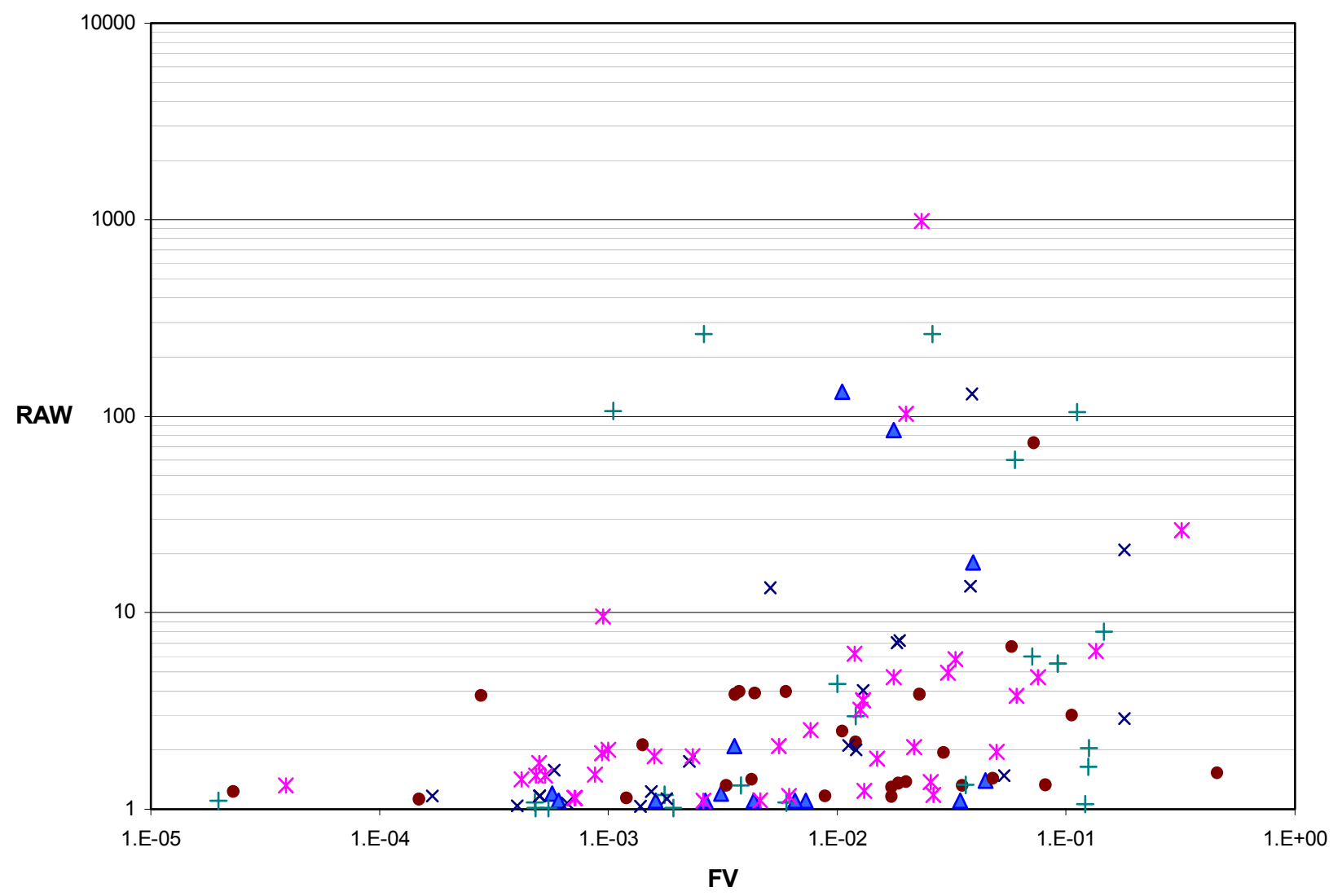

Figure 3 - Plot of 127 Human Actions from 5 PSAs

The second prong of the approach to address the question of the appropriate thresholds was empirical and consisted of forming three expert panels. BNL selected a stratified sample of 30 human actions from the set of 127 above and provided only descriptions of the actions to the panels. Each panel consisted of three NRC personnel: an operations specialist, a human factors practitioner, and a PSA expert. They were asked to decide into which of the three human factors review regions each of the 30 HAs would most appropriately fall. The panels were convened, given instructions and they produced their ratings. In evaluating the panel data, the three expert panels gave clearly different evaluations. The correlation numbers between the panels varied from 0.186 to 0.241 , which is quite low, indicating no meaningful correlation from one panel to the next. (The correlation should be $>0.36$ for some statistical significance.) We also combined the expert panels' ratings and then compared the joint panel rating with the risk (both FV and RAW) values for the HAs. We plotted the values from the panels to see what, if any, natural clustering took place into risk regions. None was identified

When these two approaches did not bear fruit, BNL derived thresholds for RAW and FV from first principles and expert judgement. This was done as follows.

The overall risk importance of a modification is judged by using RG 1.174 directly. Then if the modification contains HAs that may need to be reviewed, a further risk screening of the HA would be performed using a RAW and FV method. Based on the results discussed above, we decided to evaluate the HA against RAW and FV separately. For each of those evaluations we derived threshold or split criteria to divide the risk plane into three Regions. Thus we developed two graphs, one of RAW versus the new baseline CDF and the second of FV versus the new baseline CDF. The RAW plot (Figure 4) will be discussed here. The plot was divided into three Regions. For the threshold line dividing Regions I and II, we used the Commission's safety goal of not exceeding 1x E-4 core damage events per reactor year. We note that exceeding the E- 4 value also corresponds to a Red finding in the new Significance Determination Process (SDP) as part of the new NRC Reactor Oversight Program [14]. We would like to ensure with high confidence that the $\triangle \mathrm{CDF}$ remains less than E-4 for a modified HA. Therefore we will apply this criteria to the case when the HA fails. As a result we will define the threshold of Region I to be that combination of RAW values and baseline CDF that equate to a $\triangle \mathrm{CDF}$ of E-4.

We define the Region II and Region III threshold line similarly to RG 1.174, in that we place this line one order of magnitude below the Region I/Region II line. Using the terminology of above, this equates the lower portion of Region II to a $\Delta \mathrm{CDF}$ of E-5. Also Region II corresponds in risk importance to a Yellow finding in the new Significance Determination Process (SDP). Region III would correspond to a White or Green SDP finding. See Figure 4 below for an illustration of the RAW versus new baseline CDF curves. 
Figure 4 also contains the 127 data points of HAs plotted on it to show how they are distributed between the three Regions. This provides 35 in Region I, 41 in Region II, and 51 in Region III. The NRC staff is evaluating this latest method of screening for risk- important HAs with the anticipation that it will be incorporated as part of final guidance in a Revision to the NRC Standard Review Plan.

\section{RAW vs Baseline CDF}

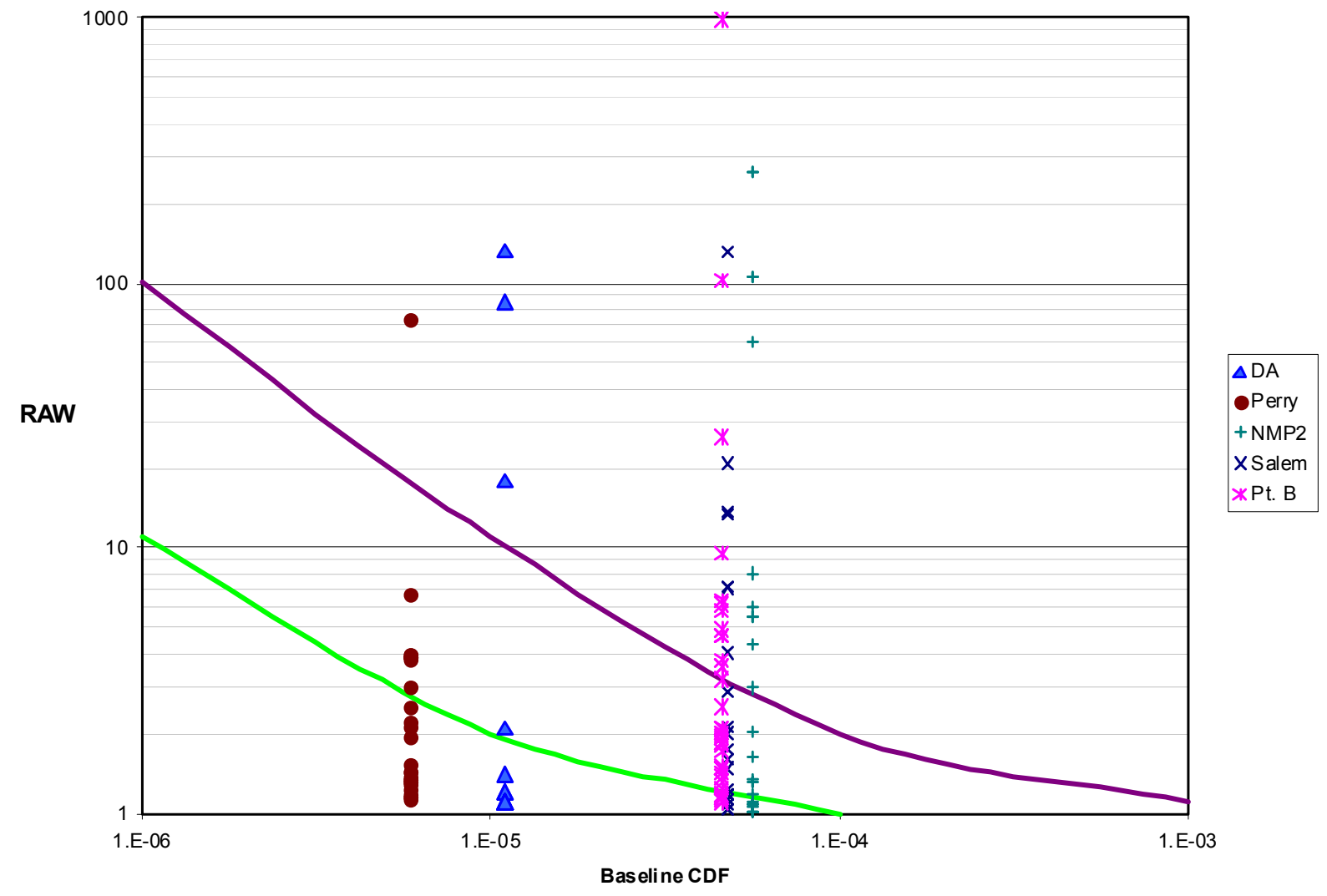

Figure 4 - Illustration of Thresholds between Regions I, II, and III

\section{Testing}

In order to evaluate the risk screening methods developed, BNL developed and ran a series of tests. The intent of this testing was to evaluate the proposed risk screening methods to determine their:

- $\quad$ Practicality - Are the methods practical?

- $\quad$ Reasonableness - Do they give reasonable results?

- $\quad$ Consistency - Do the tables yield results similar to detailed PSA calculations?

- Conservatism - How conservative are the methods?

- Discriminability - Do they sort cases into different risk regions?

- Objectivity - Can the methods be objectively applied?
Several approaches were used to perform the test and evaluation of the initial methods proposed in NUREG/CR-6689 [10]. First of all, we note that none of the 21 operator action cases previously reviewed by NRC in the mid-1990s [5] provided quantitative risk calculations related to the actions in question. Thus, these couldn't be used for testing of the quantitative screening methods developed.

The following two plant specific calculations were performed:

- Two model cases were developed from a NUREG1150 -BWR PSA to simulate actual plant changes and these were quantified using the SAPHIRE PSA model.

- $\quad$ Selected all human actions modeled in 3 IPEs and tested the RAW calculations for each action.

The testing was documented [15] and showed that the methods of [10] were generally workable and gave reasonable results. Additional testing of the new proposed methods will be performed. 


\section{Lessons Learned}

One of the key lessons learned was the importance of buy-in from the various interested parties. Since the use of PSA and the development of PSA-related applications is still an evolving field, there are various methods that can be used for any given desired application. Some of these methods have received wider application to date than others. And as a result, people are more comfortable with certain approaches and measures. Also, the selection of acceptance criteria is somewhat judgmental, since it ultimately boils down the question, "How safe is safe enough?" Thus, as the methods are being proposed and developed, it is very beneficial to obtain input from the various stakeholders. This will help to ensure that any concerns, associated with the various proposed methods, measures, and acceptance criteria, are identified and appropriately addressed.

\section{Acknowledgments}

The authors would like to thank the following NRC staff members for their valuable comments received during this program: Mike Cheok, Mark Cunningham, Dick Eckenrode, Greg Galletti, Erasmia Lois, Gareth Parry, and Nathan Siu.

\section{References}

[1] NRC (1991). Generic Letter 91-18: Information to Licensees Regarding Two NRC Inspection Manual Sections on Resolution of Degraded and Non-Conforming Conditions an on Operability. Washington, D.C.: U. S. Nuclear Regulatory Commission.

[2] NRC (1997). Information Notice 97-78: Crediting of Operator Actions in Place of Automatic Actions and Modifications of Operator Actions, Including Response Times. Washington, D.C.: U. S. Nuclear Regulatory Commission.

[3] O'Hara, J., Higgins, J., Stubler, W., Goodman, C., Eckenrode, R., Bongarra, J., and Galletti, G. (1994), Human Factors Engineering Program Review Model (NUREG-0711). Washington, D.C.: U.S. Nuclear Regulatory Commission.
[4] NRC (1996b), Human-System Interface Design Review Guideline (NUREG-0700, Rev. 1). Washington, D.C.: U.S. Nuclear Regulatory Commission.

[5] NRC (1986). Safety Goals for the Operations of Nuclear Power Plants; Policy Statement. Federal Register, Vol. 51, p. 30028 (51 FR 30028), August 4, 1986.

[6] Higgins, J., O'Hara, J., Stubler, W., \& Deem, R. (1999). Summary of Credit of past Operator Action Cases (Report No. W6022-T1-1-7/99). Upton, New York: Brookhaven National Laboratory.

[7] NRC (1998). An Approach for Using Probabilistic Risk Assessment in Risk-informed Decisions on Plant-specific Changes to the Licensing Basis (Regulatory Guide 1.174).Washington, D.C.: U.S. Nuclear Regulatory Commission.

[8] NRC (1998b). An approach for using Plant-Specific, Risk-Informed Decisionmaking: Technical Specifications, August, 1998 (Regulatory Guide 1.177).Washington, D.C.: U.S. Nuclear Regulatory Commission.

[9] Azarm, M.; Higgins, J., and Chu, T. (1999). Development of a Riskinformed Baseline Inspection Program. Upton, New York. Brookhaven National Laboratory.

[10] Higgins, J. and O'Hara, J. (2000). Proposed Approach for Reviewing Changes to Risk-Important Human Actions (NUREG/CR-6689). Washington, D.C.: U.S. Nuclear Regulatory Commission.

[11] Vesely, W., Davis, T., Denning, R., and Saltos, N. (1983). Measures of Risk Importance and Their Applications (NUREG/CR-3385). Washington, DC: U.S. Nuclear Regulatory Commission.

[12] NRC SER for the Graded QA Implementation Plan at South Texas, dated 10/6/1997.

[13] NRC SER for the Risk-Informed Inservice Testing (IST) Program at Comanche Peak, dated 8/14/1998.

[14] NRC (1999). New NRC Reactor Inspection and Oversight Program, NUREG-1649, February, 1999.

[15] O'Hara, J. and Higgins, J., The Development of a Proposed Approach for Reviewing Plant Modifications Involving Risk-Important Human Actions (Draft NUREG/CR-6693 ). Washington, D.C.: U.S. Nuclear Regulatory Commission. (October, 2000) 